\title{
Review Article Efficacy of Telmisartan Plus Amlodipine in Nonresponders to CCB Monotherapy
}

\author{
Steen Neldam, ${ }^{1}$ Dingliang $\mathrm{Zhu}^{2}{ }^{2}$ and Helmut Schumacher ${ }^{3}$ \\ ${ }^{1}$ Rodøvre Centrum 294, 2610 Rodøvre, Denmark \\ ${ }^{2}$ Shanghai Ruijin Hospital, Shanghai Institute of Hypertension, 197 Ruijin 2nd Road, Shanghai, China \\ ${ }^{3}$ Boehringer Ingelheim Pharma GmbH \& Co. KG, Binger Strasse 173, 55216 Ingelheim am Rhein, Germany
}

Correspondence should be addressed to Helmut Schumacher; helmut.schumacher@boehringer-ingelheim.com

Received 16 January 2013; Accepted 20 May 2013

Academic Editor: M. Volpe

Copyright (C) 2013 Steen Neldam et al. This is an open access article distributed under the Creative Commons Attribution License, which permits unrestricted use, distribution, and reproduction in any medium, provided the original work is properly cited.

\begin{abstract}
Hypertensive patients unable to reach blood pressure (BP) targets with antihypertensive monotherapy may be switched to a combination of two medications with complementary modes of action for improved treatment response. This post hoc analysis pools data from 2812 patients, 1891 of whom were not at goal (diastolic BP [DBP] $<90 \mathrm{~mm} \mathrm{Hg}$ ) with amlodipine $5 \mathrm{mg}$ (A5) monotherapy who subsequently switched to telmisartan 40 or $80 \mathrm{mg}$ (T80)/A5 single-pill combination (SPC) or amlodipine $10 \mathrm{mg}$ (A10) monotherapy, and considers an additional 921 patients, 616 of whom were not at goal with A10 monotherapy who switched to telmisartan/amlodipine SPC. Patients switched to telmisartan/amlodipine SPC achieved significantly greater BP reductions compared with continued monotherapy $(P<0.0001)$ with reductions of $-15.2 /-10.9 \mathrm{~mm} \mathrm{Hg}$ seen with T80/A5 after 8 weeks in patients switched from A5. BP goal $(<140 / 90 \mathrm{~mm} \mathrm{Hg})$, systolic BP goal $(<140 \mathrm{~mm} \mathrm{Hg})$, and DBP goal $(<90 \mathrm{~mm} \mathrm{Hg})$ were reached by significantly more patients with telmisartan/amlodipine than with monotherapy $(P<0.0001$ for all comparisons; $56.1 \%, 69.7 \%$, and $66.9 \%$, resp., in patients who switched from A5 to T80/A5). Early use of such combination therapy should be considered to quickly reach BP targets, particularly in patients with added risk.
\end{abstract}

\section{Introduction}

Hypertension is a major risk factor for cardiovascular (CV) and cerebrovascular morbidity and mortality [1]. Achieving blood pressure (BP) goal rapidly, as well as sustaining this level of control, is important to reduce CV risk and prevent organ damage [2]. Treatment guidelines generally recommend treatment of hypertension with a BP goal $<140 / 90 \mathrm{~mm} \mathrm{Hg}$ for the majority of patients. More aggressive targets of $<130 / 80 \mathrm{~mm} \mathrm{Hg}$ in patients with diabetes or renal disease have also been suggested [3,4], although such low BP targets have been recently questioned following inconclusive results from several trials [2, 5-7]. Despite these recommendations, less than one-third of patients taking hypertensive treatment reach the desired goal of $<140 / 90 \mathrm{~mm} \mathrm{Hg}$ [8], and many of these will be taking only one antihypertensive agent.

Combining two drugs from different classes with complementary mechanisms of action is likely to result in additional reductions in BP compared with either agent used alone $[9$, 10]. For this reason and based upon evidence from many antihypertensive studies, most guidelines agree that the majority of patients need combination therapy to achieve BP goals, and so initial combination therapy is now more frequently recommended [3, 4, 11, 12]. Single-pill combinations (SPCs) can also help overcome the poor treatment adherence that has been associated with free combination therapies with multiple antihypertensive agents, administered at different time intervals, and, therefore, patients are more likely to reach and maintain their BP goal and reduce their CV risk [13]. A calcium channel blocker (CCB) combined with a reninangiotensin system (RAS) inhibitor (such as an angiotensin II receptor blocker [ARB] or an angiotensin-converting enzyme inhibitor) is one such complimentary combination. Indeed, based on outcomes from the avoiding cardiovascular events through combination therapy in patients living with systolic hypertension (ACCOMPLISH) trial, in which a RAS 
TABLE 1: Details of trials identified for inclusion into the analysis.

\begin{tabular}{|c|c|c|c|c|c|}
\hline Trial & Description & $\begin{array}{l}\text { Patient } \\
\text { numbers }\end{array}$ & $\begin{array}{l}\text { Study duration } \\
\text { (weeks) }\end{array}$ & $\begin{array}{l}\text { Run-in treatment } \\
\text { (weeks) }\end{array}$ & $\begin{array}{c}\text { Randomized } \\
\text { treatments ( } 8 \text { weeks) }\end{array}$ \\
\hline $\begin{array}{l}\text { NCT00558428 } \\
\text { Neldam et al. } 2011[20]\end{array}$ & $\begin{array}{l}\text { A5 nonresponder } \\
\text { trial (TEAMSTA-5) }\end{array}$ & 1057 & 8 & A5 (6) & $\begin{array}{c}\text { A5, A10, T40/A5, } \\
\text { T80/A5 }\end{array}$ \\
\hline $\begin{array}{l}\text { NCT00558064 } \\
\text { Boehringer Ingelheim data on file } \\
{[26]}\end{array}$ & $\begin{array}{c}\mathrm{T} 40 / \mathrm{A} 5 \text { in } \mathrm{A} 5 \\
\text { nonresponder trial }\end{array}$ & 520 & 8 & A5 (6) & A5, T40/A5 \\
\hline $\begin{array}{l}\text { NCT01103960 } \\
\text { Boehringer Ingelheim data on file } \\
\text { [27] }\end{array}$ & $\begin{array}{l}\text { T80/A5 in A5 } \\
\text { nonresponder trial }\end{array}$ & 314 & 8 & A5 (6) & A5, T80/A5 \\
\hline $\begin{array}{l}\text { NCT00553267 } \\
\text { Neldam et al. } 2011 \text { [25] }\end{array}$ & $\begin{array}{l}\text { A10 nonresponder } \\
\text { trial (TEAMSTA-10) }\end{array}$ & 921 & 8 & A5 (2), A10 (6) & $\begin{array}{l}\mathrm{A} 10, \mathrm{~T} 40 / \mathrm{A} 10 \\
\mathrm{~T} 80 / \mathrm{A} 10\end{array}$ \\
\hline
\end{tabular}

A5: amlodipine $5 \mathrm{mg}$; A10: amlodipine $10 \mathrm{mg}$; T40: telmisartan $40 \mathrm{mg}$; T80: telmisartan $80 \mathrm{mg}$; TEAMSTA-5: telmisartan/amlodipine single-pill study to assess the efficacy in patients with essential hypertension not controlled on A5; TEAMSTA-10: telmisartan/amlodipine single-pill study to assess the efficacy in patients with essential hypertension not controlled on A10.

inhibitor/CCB was superior to a RAS inhibitor/diuretic [14], this combination was particularly effective in reducing $\mathrm{CV}$ risk and is recommended by guidelines $[3,4,12]$.

Telmisartan is the longest acting of all ARBs with a halflife of 24 hours [15] and has been shown to reduce CV risk [16], leading to an indication for the reduction of $\mathrm{CV}$ morbidity in patients with manifest atherothrombotic CV disease (history or coronary heart disease, stroke, or peripheral arterial disease) or type 2 diabetes mellitus with documented target organ damage [15]. When combined with the $\mathrm{CCB}$, amlodipine, additive BP lowering is evident, compared with the individual monotherapies $[17,18]$. This telmisartan/amlodipine combination has also been demonstrated to be effective in patients at all stages of hypertension, as well as in those with added risk factors including obesity, diabetes, or metabolic syndrome [19-24].

Several published studies have demonstrated the efficacy of the telmisartan/amlodipine combination in patients uncontrolled on amlodipine monotherapy [20,25]; however, a pooled analysis incorporating a large population is currently lacking. This paper presents a post hoc analysis of data from the Boehringer Ingelheim clinical trials database comparing telmisartan/amlodipine in combination therapy versus amlodipine monotherapy in patients who were uncontrolled with amlodipine alone. Where appropriate, data was pooled across studies and analyzed.

Only trials from the Boehringer Ingelheim database were chosen as no other relevant studies could be found using other databases. This also enabled access to patient-level data and to ensure consistency in the recording of outcomes.

\section{Methods}

2.1. Studies. The Boehringer Ingelheim trial database was searched for all studies investigating the telmisartan/amlodipine SPC therapy in hypertensive patients uncontrolled on any CCB monotherapy. Four randomized, double-blind studies, completed between September 2008 and August 2011, were identified, and these are detailed in Table 1. All studies included a 6-8-week amlodipine monotherapy (5 or $10 \mathrm{mg}$ ) run-in period, and patients who had not reached the diastolic BP (DBP) goal of $\geq 90 \mathrm{~mm} \mathrm{Hg}$ following this runin period were then randomized to amlodipine monotherapy or telmisartan/amlodipine SPC therapy for a further 8 weeks. Three of the studies (telmisartan/amlodipine singlepill study to assess the efficacy in patients with essential hypertension not controlled on A5 [TEAMSTA-5], T40/A5 in A5 nonresponders, and T80/A5 in A5 nonresponders) included patients uncontrolled on amlodipine $5 \mathrm{mg}$ (A5) at the end of the run-in period of 6 weeks, and the fourth study (telmisartan/amlodipine single-pill study to assess the efficacy in patients with essential hypertension not controlled on A10 [TEAMSTA-10]) included patients uncontrolled on amlodipine $10 \mathrm{mg}(\mathrm{A} 10)$ at the end of the run-in period. In the TEAMSTA-10 study, the run-in period was longer as patients began treatment with $\mathrm{A} 5$ for 2 weeks before being uptitrated to A10 for a further 6 weeks.

During the randomized phases of the studies, the treatment regimens used were A5, A10, telmisartan $40 \mathrm{mg}$ (T40)/A5, telmisartan $80 \mathrm{mg}$ (T80)/A5, T40/A10, and T80/ A10. In all studies, patients took their trial treatments once daily, in the morning. Seated BP was measured using a standard, validated, and calibrated sphygmomanometer. BP was measured at baseline (week 0), week 4 , and week 8 in the three studies involving patients uncontrolled on A5, at baseline, and at weeks 2,6 , and 8 in the one study that included patients uncontrolled on A10. The change from reference baseline (i.e., after amlodipine monotherapy) in seated trough DBP was the primary endpoint in all four studies.

2.2. Statistical Analysis. Due to the similarities in trial design, data from the three trials in patients uncontrolled on A5 were pooled and analyzed. However, data from the one study in patients uncontrolled on A10 were analyzed separately.

The mean changes in seated DBP and systolic BP (SBP) from reference baseline, adjusted for baseline BP and study (where appropriate), were calculated, and treatments were 
TABLE 2: Demographic and baseline data.

\begin{tabular}{|c|c|c|c|c|c|c|c|}
\hline & \multicolumn{4}{|c|}{ A5 run-in } & \multicolumn{3}{|c|}{ A10 run-in } \\
\hline & A10 & A5 & T40/A5 & T80/A5 & A10 & $\mathrm{T} 40 / \mathrm{A} 10$ & T80/A10 \\
\hline Number of patients & 261 & 671 & 533 & 426 & 305 & 306 & 310 \\
\hline Age, years mean (SD) & $54.3(10.7)$ & $54.4(10.2)$ & $55.4(10.4)$ & $53.8(9.8)$ & $56.4(10.4)$ & $57.7(9.4)$ & $55.4(9.8)$ \\
\hline BMI, $\mathrm{kg} / \mathrm{m}^{2}$ mean, (SD) & $28.6(4.9)$ & $27.1(4.8)$ & $27.5(5.0)$ & $28.4(5.0)$ & $30.2(4.4)$ & $29.6(4.4)$ & $30.7(4.9)$ \\
\hline Female, \% & 35.2 & 36.7 & 34.7 & 39.9 & 41.3 & 47.1 & 46.1 \\
\hline \multicolumn{8}{|l|}{ Race } \\
\hline Asian, \% & 20.3 & 69.9 & 60.0 & 49.1 & 0 & 0 & 0.6 \\
\hline Black, \% & 2.3 & 0.6 & 0.6 & 0.9 & 0 & 0 & 0.3 \\
\hline White, \% & 76.6 & 29.5 & 39.2 & 49.8 & 100 & 99.3 & 98.7 \\
\hline Other, \% & 0.8 & 0 & 0.2 & 0.2 & 0 & 0.3 & 0 \\
\hline Missing, \% & 0 & 0 & 0 & 0 & 0 & 0.3 & 0.3 \\
\hline Diabetes \% & 8.0 & 12.4 & 15.0 & 8.7 & 12.1 & 11.4 & 14.8 \\
\hline Baseline DBP, mean (SD) & $96.5(4.8)$ & $96.4(5.5)$ & $96.4(5.1)$ & $96.7(5.1)$ & $95.6(4.0)$ & $95.5(4.0)$ & $95.6(4.1)$ \\
\hline Baseline SBP, mean (SD) & $149.0(11.8)$ & $147.5(12.0)$ & $147.2(12.3)$ & $147.9(11.9)$ & $146.8(10.2)$ & $148.1(9.4)$ & $147.4(9.4)$ \\
\hline $\begin{array}{l}\text { Duration of hypertension, } \\
\text { years, mean (SD) }\end{array}$ & $6.5(8.0)$ & $6.9(7.8)$ & $6.0(7.4)$ & $6.7(7.8)$ & $8.1(7.1)$ & $8.1(7.7)$ & $8.0(7.5)$ \\
\hline
\end{tabular}

A5: amlodipine $5 \mathrm{mg}$; A10: amlodipine $10 \mathrm{mg}$; BMI: body mass index; DBP: diastolic blood pressure; SBP: systolic blood pressure; SD: standard deviation; T40: telmisartan $40 \mathrm{mg}$; T80: telmisartan $80 \mathrm{mg}$.

compared using analysis of covariance. Other measures included BP goal ( $<140 / 90 \mathrm{~mm} \mathrm{Hg})$, DBP goal $(<90 \mathrm{~mm} \mathrm{Hg})$, and SBP goal $(<140 \mathrm{~mm} \mathrm{Hg})$ attainment rates, in addition to response rates for DBP $(<90 \mathrm{~mm} \mathrm{Hg}$ or a reduction $\geq 10 \mathrm{~mm} \mathrm{Hg})$ and SBP $(<140 \mathrm{~mm} \mathrm{Hg}$ or a reduction $\geq 20 \mathrm{~mm} \mathrm{Hg}$ ). The goal and response rates were compared between treatments using logistic regression adjusted for baseline BP and study.

\section{Results}

3.1. Demographics. A total of 2812 patients were included in this analysis-1891 not achieving DBP goal $<90 \mathrm{~mm} \mathrm{Hg}$ on A5 monotherapy and 921 not achieving the same DBP goal on A10. For the analysis in patients not at goal on A5 monotherapy, groups were generally well matched for most demographic characteristics (Table 2). However, the T80/A5 group had slightly more females (39.9\% compared with $34.7-$ $36.7 \%$ in the other groups); the A5 and T40/A5 groups had higher proportions of Asian patients (69.9\% and 60.0\%, resp.) than the A10 and T80/A5 groups (20.3\% and 49.1\%), due to the inclusion of two Asian studies that did not contain A10 as a treatment. The baseline SBP in the A10 group was lower than in the other groups $(140.9 \mathrm{~mm} \mathrm{Hg}$ versus $147.2-147.9 \mathrm{~mm} \mathrm{Hg})$. The baseline SBP in the A10 group was lower than in the other groups $(140.9 \mathrm{~mm} \mathrm{Hg}$ versus $147.2-$ $147.9 \mathrm{~mm} \mathrm{Hg}$ ). Considering those patients not at goal on A10 monotherapy, the groups were very well matched, with only the A10 group having fewer females (41.3\%) compared with the T40/A10 and T80/A10 groups (47.1\% and 46.1\%, resp.) (Table 2).
3.2. Change in DBP/SBP from Baseline. All patients achieved significantly greater reductions in DBP and SBP when switched to telmisartan/amlodipine SPC therapy, compared with patients who continued on monotherapy $(P<0.0001)$. After 8 weeks of randomized treatment, patients not at DBP goal ( $<90 \mathrm{~mm} \mathrm{Hg}$ ) on A5 monotherapy who were maintained on A5 achieved DBP changes (from reference baseline) of $-6.7 \mathrm{~mm} \mathrm{Hg}$ (95\% confidence interval [CI], -7.2, -6.1), and those who were uptitrated to A10 achieved DBP reductions of $-8.8 \mathrm{~mm} \mathrm{Hg}$ (95\% CI, $-9.8,-7.8 ; P=0.0003$ versus A5). Those patients who switched to T40/A5 and T80/A5 achieved DBP reductions of $-10.7 \mathrm{~mm} \mathrm{Hg}$ (95\% CI, -11.4 , $-10.0 ; P<0.0001$ versus $A 5 ; P=0.0011$ versus $A 10)$ and $-10.9 \mathrm{~mm} \mathrm{Hg}$ (95\% CI, $-11.6,-10.1 ; P<0.0001$ versus $\mathrm{A} 5$; $P=0.0005$ versus A10), respectively. Adjusted mean changes in SBP from baseline at 8 weeks were $-7.8 \mathrm{~mm} \mathrm{Hg}(95 \%$ CI, $-8.6,-6.9)$ for patients maintained on A5 monotherapy, $-12.1 \mathrm{~mm} \mathrm{Hg}$ (95\% CI, $-13.6,-10.6 ; P<0.0001$ versus A5) for patients uptitrated to A10 monotherapy, $-14.6 \mathrm{~mm} \mathrm{Hg}(95 \%$ CI, $-15.7,-13.6 ; P<0.0001$ versus A5; $P=0.0032$ versus A10) for patients switched to T40/A5, and $-15.2 \mathrm{~mm} \mathrm{Hg}$ (95\% CI, $-16.3,-14.0 ; P<0.0001$ versus $A 5 ; P=0.0005$ versus $A 10)$ for patients switched to T80/A5 (Figure 1).

In those patients who had not reached goal (DBP < $90 \mathrm{~mm} \mathrm{Hg}$ ) with A10 monotherapy, DBP was reduced by $-6.1 \mathrm{~mm} \mathrm{Hg}(95 \% \mathrm{CI},-6.8,-5.4)$ when maintained on A10 for a further 8 weeks; $-8.9 \mathrm{~mm} \mathrm{Hg}$ when switched to T40/A10 (95\% CI, $-9.6,-8.1 ; P<0.0001$ versus $\mathrm{A} 10)$; and $-8.9 \mathrm{mmHg}$ when switched to T80/10 (95\% CI, -9.6, -8.2; $P<0.0001$ versus A10). Adjusted mean changes in SBP from baseline at 8 weeks were $-6.9 \mathrm{~mm} \mathrm{Hg}(95 \% \mathrm{CI},-7.9,-5.8)$ for patients 
TABLE 3: OR for goal attainment and response rates in patients not at goal with A5 monotherapy.

\begin{tabular}{lccr}
\hline Goal or response target $(\mathrm{mm} \mathrm{Hg})$ & $\begin{array}{c}\text { A10 versus A5 } \\
\text { OR }(95 \% \mathrm{CI})\end{array}$ & $\begin{array}{c}\text { T40/A5 versus A5 } \\
\text { OR }(95 \% \mathrm{CI})\end{array}$ & $\begin{array}{c}\text { T80/A5 versus A5 } \\
\text { OR }(95 \% \text { CI })\end{array}$ \\
\hline $\mathrm{BP}<140 / 90$ & $2.13(1.49,3.05)$ & $3.07(2.34,4.04)$ & $3.43(2.54,4.64)$ \\
$\mathrm{DBP}<90$ & $2.24(1.58,3.19)$ & $2.62(2.00,3.44)$ & $3.00(2.22,4.07)$ \\
$\mathrm{DBP}<90$ or reduction $\geq 10$ & $2.12(1.53,2.96)$ & $2.71(2.10,3.51)$ & $2.73(2.05,3.65)$ \\
$\mathrm{SBP}<140$ & $1.94(1.35,2.81)$ & $2.99(2.24,4.00)$ & $3.25(2.37,4.48)$ \\
$\mathrm{SBP}<140$ or reduction $\geq 20$ & $1.90(1.36,2.68)$ & $2.69(2.06,3.52)$ & $2.86(2.11,3.90)$ \\
\hline
\end{tabular}

A5: amlodipine $5 \mathrm{mg}$; A10: amlodipine $10 \mathrm{mg}$; BP: blood pressure; CI: confidence interval; DBP: diastolic blood pressure; OR: odds ratio; SBP: systolic blood pressure; T40: telmisartan $40 \mathrm{mg}$; T80: telmisartan $80 \mathrm{mg}$.

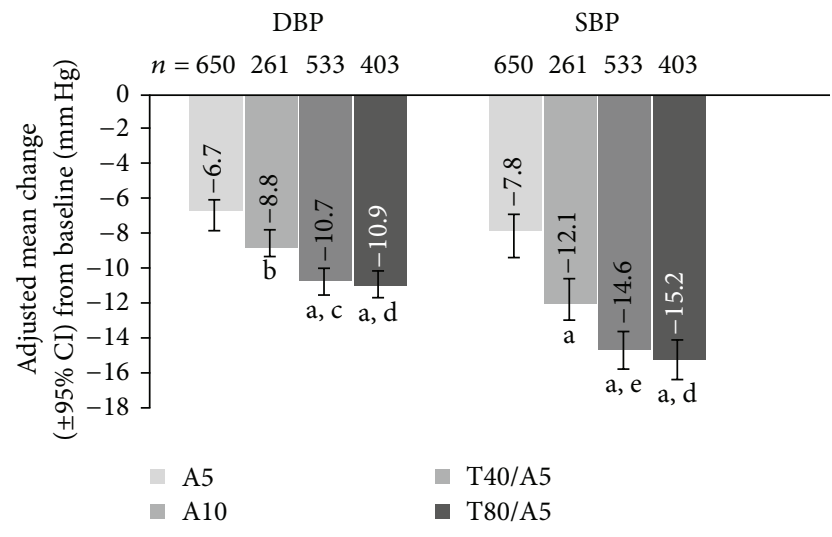

Figure 1: Adjusted mean change in DBP and SBP at week 8 from baseline in patients uncontrolled on A5 monotherapy. A5: amlodipine $5 \mathrm{mg}$; A10: amlodipine $10 \mathrm{mg}$; CI: confidence interval; DBP: diastolic blood pressure; SBP: systolic blood pressure; T40: telmisartan $40 \mathrm{mg}$; T80: telmisartan $80 \mathrm{mg}$. ${ }^{\mathrm{a}} \mathrm{P}<0.0001$ versus $\mathrm{A} 5$; ${ }^{\mathrm{b}} P=0.0003$ versus $A 5 ;{ }^{\mathrm{c}} P=0.0011$ versus $\mathrm{A} 10 ;{ }^{\mathrm{d}} P=0.0005$ versus $\mathrm{A} 10 ;{ }^{\mathrm{e}} \mathrm{P}=0.0032$ versus $\mathrm{A} 10$.

remaining on A10 monotherapy, $-10.5 \mathrm{~mm} \mathrm{Hg}$ (95\% CI, -11.6, -9.5; $P<0.0001$ versus A10) for patients switched to T40/ $\mathrm{A} 10$, and $-10.7 \mathrm{~mm} \mathrm{Hg}$ (95\% CI, $-11.8,-9.7 ; P<0.0001$ versus A10) for patients switched to T80/A10 (Figure 2).

3.3. Goal Attainment Rates. A greater proportion of patients not at DBP goal ( $<90 \mathrm{~mm} \mathrm{Hg}$ ) with amlodipine monotherapy achieved the goals of $\mathrm{BP}<140 / 90 \mathrm{~mm} \mathrm{Hg}, \mathrm{DBP}<90 \mathrm{~mm} \mathrm{Hg}$, and SBP $<140 \mathrm{~mm} \mathrm{Hg}$ when switched to telmisartan/amlodipine SPC therapy for 8 weeks compared with those who continued with amlodipine monotherapy (Figures 3(a) and 3(b)). Indeed, patients who switched to the telmisartan/amlodipine SPC therapy were significantly more likely to achieve goals than patients maintained on monotherapy (Table 3 ).

In those patients who had not previously achieved goal with A5 monotherapy, DBP goal (<90 mm Hg) was achieved by only $46.6 \%$ of patients remaining on A5 and $56.6 \%$ of patients uptitrated to A10 compared with $62.3 \%$ patients who were switched to T40/A5 and $66.9 \%$ of patients who were switched to T80/A5. Similarly, SBP goal $(<140 \mathrm{~mm} \mathrm{Hg})$ was achieved by $51.6 \%$ of those patients remaining on A5

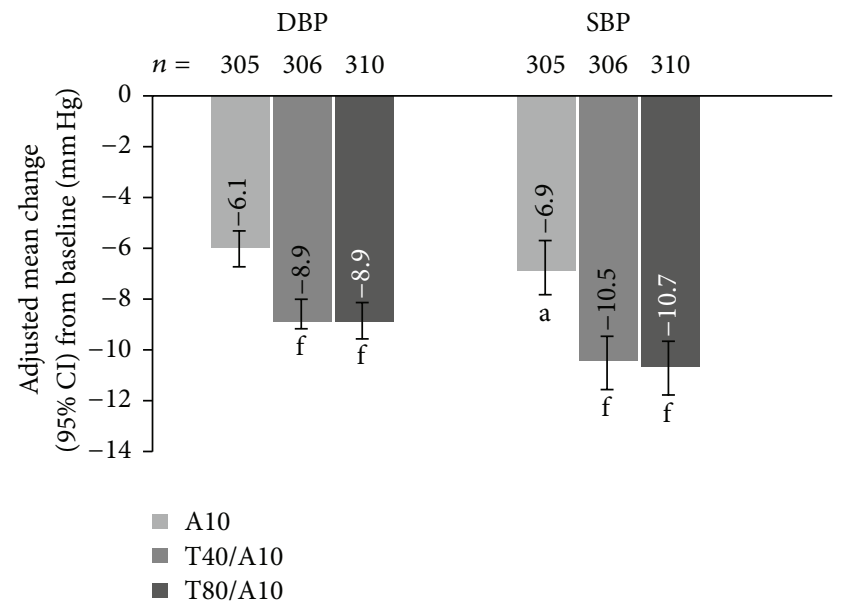

FIGURE 2: Adjusted mean change in $\mathrm{DBP}$ and SBP at week 8 from baseline in patients uncontrolled on A10 monotherapy. A10: amlodipine $10 \mathrm{mg}$; CI: confidence interval; DBP: diastolic blood pressure; SBP: systolic blood pressure; T40: telmisartan $40 \mathrm{mg}$; T80: telmisartan $80 \mathrm{mg} .{ }^{\mathrm{a}} \mathrm{P}<0.0001$ versus $\mathrm{A} 5 ;{ }^{\mathrm{f}} \mathrm{P}<0.0001$ versus A10.

monotherapy and $54.4 \%$ of those uptitrated to A10 compared with $68.9 \%$ of patients switched to T40/A5 and $69.7 \%$ who were switched to T80/A5. Overall BP goal $(<140 / 90 \mathrm{~mm} \mathrm{Hg})$ was achieved by only $33.8 \%$ of patients remaining on A5 monotherapy and $39.5 \%$ of patients uptitrated to A10 compared with $52.5 \%$ and $56.1 \%$ of patients who switched to T40/ A5 and T80/A5, respectively $(P<0.0001$ for overall treatment differences of all comparisons).

In patients not at goal with A10 monotherapy, DBP < $90 \mathrm{~mm} \mathrm{Hg}$ was achieved in only $51.1 \%$ of patients remaining on A10 compared with $63.7 \%$ of patients switched to T40/A10 and $66.5 \%$ of patients switched to T80/A10 $(P=0.0002$ for overall treatment differences). SBP $<140 \mathrm{~mm} \mathrm{Hg}$ was achieved in $50.2 \%$ of those remaining on A10 monotherapy compared with $58.8 \%$ switched to T40/A10 and $60.3 \%$ switched to T80/A10 ( $P=0.0012$ for overall treatment differences). Overall BP goal ( $<140 / 90 \mathrm{~mm} \mathrm{Hg}$ ) was achieved by only $37.0 \%$ of patients remaining on A10 monotherapy compared with $47.7 \%$ and $52.3 \%$ of patients who switched to T40/A10 and T80/A10, respectively $(P<0.0001$ for overall treatment differences). 


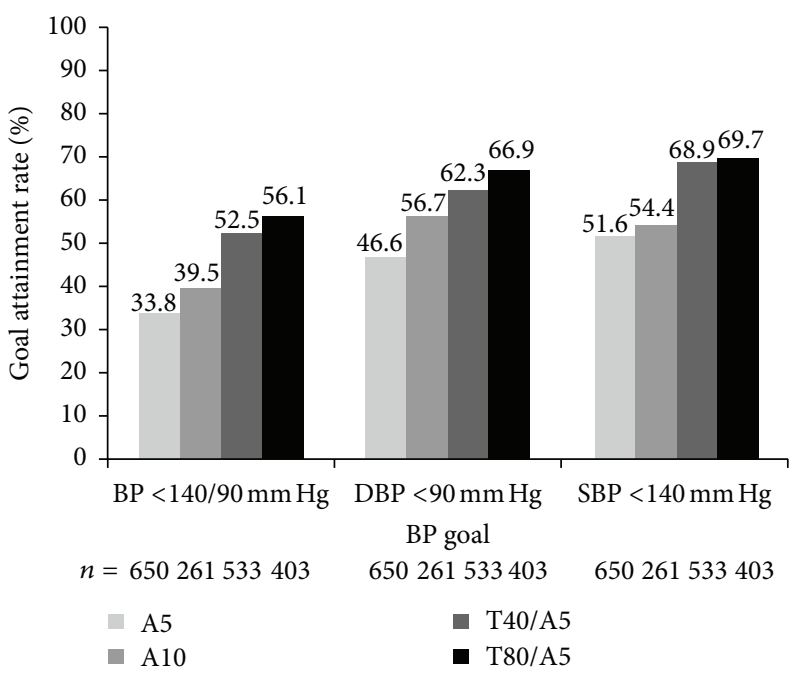

(a) Patients not at goal with A5 monotherapy

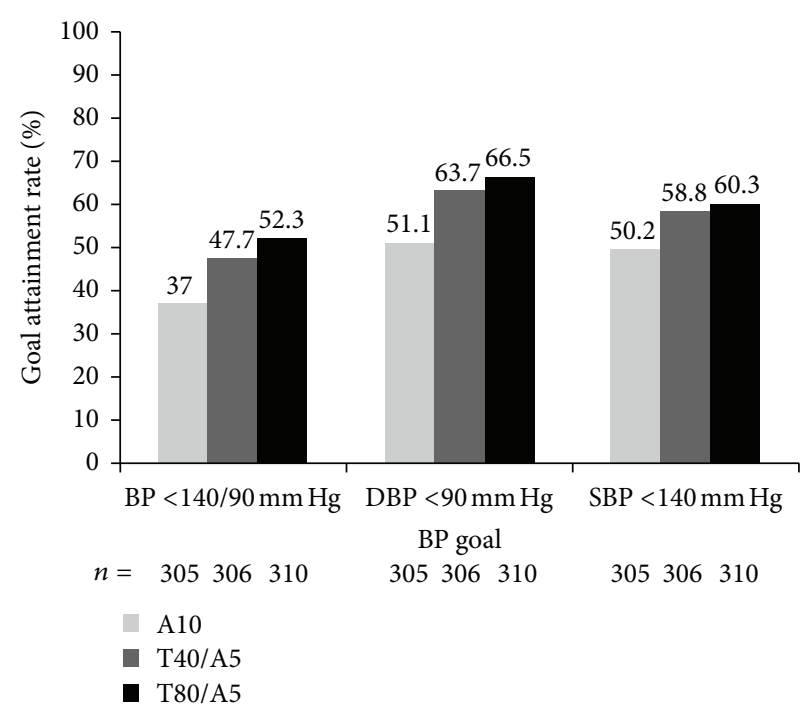

(b) Patients not at goal with A10 monotherapy

FIGURE 3: BP goal attainment rates at week 8. A5: amlodipine $5 \mathrm{mg}$; A10: amlodipine $10 \mathrm{mg}$; BP: blood pressure; DBP: diastolic blood pressure; SBP: systolic blood pressure; T40: telmisartan $40 \mathrm{mg}$; T80: telmisartan $80 \mathrm{mg}$.

TABLE 4: OR for goal attainment and response rates in patients not at goal with A10 monotherapy.

\begin{tabular}{lcc}
\hline $\begin{array}{l}\text { Goal or response target } \\
(\mathrm{mm} \mathrm{Hg})\end{array}$ & $\begin{array}{c}\text { T40/A10 versus } \\
\text { A10, } \\
\text { OR }(95 \% \mathrm{CI})\end{array}$ & $\begin{array}{c}\text { T80/A10 versus } \\
\text { O10, }\end{array}$ \\
\hline $\mathrm{BP}<140 / 90$ & $1.78(1.27,2.52)$ & $2.08(1.48,2.94)$ \\
$\mathrm{DBP}<90$ & $1.70(1.22,2.37)$ & $1.95(1.40,2.73)$ \\
$\mathrm{DBP}<90$ or reduction $\geq 10$ & $1.69(1.22,2.36)$ & $1.93(1.39,2.70)$ \\
$\mathrm{SBP}<140$ & $1.78(1.25,2.54)$ & $1.77(1.25,2.52)$ \\
$\mathrm{SBP}<140$ or reduction $\geq 20$ & $1.70(1.22,2.38)$ & $1.73(1.24,2.42)$ \\
\hline
\end{tabular}

A10: amlodipine $10 \mathrm{mg}$; BP: blood pressure; CI: confidence interval; DBP: diastolic blood pressure; OR: odds ratio; SBP: systolic blood pressure; T40: telmisartan $40 \mathrm{mg}$; T80: telmisartan $80 \mathrm{mg}$.

3.4. Response Rates. Patients not at goal with amlodipine monotherapy who received telmisartan/amlodipine SPC therapy were significantly more likely to achieve response targets than patients maintained on either monotherapy (Table 4).

Response rates (DBP $<90 \mathrm{~mm} \mathrm{Hg}$ or a reduction $\geq 10 \mathrm{~mm} \mathrm{Hg}$ or SBP $<140 \mathrm{~mm} \mathrm{Hg}$ or a reduction $\geq 20 \mathrm{~mm} \mathrm{Hg}$ ) were higher in patients randomized to telmisartan/amlodipine SPC therapy compared with response rates of patients who continued amlodipine monotherapy. In patients not at goal on A5 monotherapy, DBP response was achieved in only $51.6 \%$ of patients remaining on A5 and $62.5 \%$ of those uptitrated to A10 compared with $70.0 \%$ patients on T40/A5 and $73.0 \%$ of patients on T80/A5 $(P<0.0001$ for overall treatment differences). SBP response was achieved in $57.8 \%$ of those remaining on $\mathrm{A} 5$ and $63.6 \%$ of those uptitrated to A10 compared with $74.3 \%$ on T40/A5 and $77.7 \%$ on T80/A5 ( $P<0.0001$ for overall treatment differences). In patients not at goal on A10 monotherapy, DBP response was achieved in only $53.4 \%$ of patients remaining on A10 compared with $66.0 \%$ patients on T40/A10 and $68.7 \%$ of patients on T80/A10 ( $P=0.0002$ for overall treatment differences). SBP response was achieved in $54.1 \%$ of those remaining on A10 compared with $64.7 \%$ on T40/A10 and $65.8 \%$ on T80/A10 $(P=0.0013$ for overall treatment differences).

3.5. Adverse Events. In patients not at goal with A5 monotherapy, those who continued on A5 monotherapy experience a similar rate of drug-related adverse events and discontinuations due to adverse events compared with those who switched to either SPC dose (Table 5). However, those who switched to A10 monotherapy experienced numerically more drug-related adverse events and discontinuations due to adverse events. In patients not at goal with A10 monotherapy, the rates of respective AEs were similar in all three treatment groups. The number of serious adverse events reported in all groups was very low, irrespective of run-in medication. Interestingly, peripheral oedema mainly occurred in the European studies (A5 and A10 nonresponder trials), whereas in the Asian studies (T40/A5 in the A5 nonresponder trial and T80/A5 in the A5 nonresponder trial), peripheral oedema was not reported as frequently. In the A5 nonresponder trial, peripheral oedema was reported as follows: A10: $74(26.8 \%)$, A5: 22 (8.2\%), T40/A5: 14 (5.1\%), and T80/A5: 10 (3.6\%). In the A10 nonresponder trial, the respective numbers were A10: 22 (7.0\%), T40/A10: 21 (6.7\%), and T80/A10: 27 (8.5\%).

\section{Discussion}

In this analysis of 2812 patients who failed to reach DBP goal ( $<90 \mathrm{~mm} \mathrm{Hg}$ ) with amlodipine monotherapy after 6-8 weeks of treatment, use of telmisartan/amlodipine SPC therapy was associated with significantly greater reductions in DBP 
TABle 5: Adverse event data.

\begin{tabular}{|c|c|c|c|c|c|c|c|}
\hline & \multicolumn{4}{|c|}{ A5 run-in } & \multicolumn{3}{|c|}{ A10 run-in } \\
\hline & A10 & A5 & T40/A5 & T80/A5 & A10 & $\mathrm{T} 40 / \mathrm{A} 10$ & $\mathrm{~T} 80 / \mathrm{A} 10$ \\
\hline Number of patients treated* & 276 & 693 & 546 & 437 & 315 & 315 & 317 \\
\hline $\begin{array}{l}\text { Patients with investigator } \\
\text { defined drug-related AEs (\%) }\end{array}$ & $77(27.9)$ & $43(6.2)$ & $32(5.9)$ & $27(6.2)$ & $27(8.6)$ & $25(7.9)$ & $31(9.8)$ \\
\hline $\begin{array}{l}\text { Patients with AEs leading to } \\
\text { discontinuation (\%) }\end{array}$ & $21(7.6)$ & $9(1.3)$ & $6(1.1)$ & $5(1.1)$ & $7(2.2)$ & $9(2.9)$ & $4(1.3)$ \\
\hline Patients with SAEs (\%) & $1(0.4)$ & $4(0.6)$ & $3(0.5)$ & $1(0.2)$ & $1(0.3)$ & $3(1.0)$ & $0(0.0)$ \\
\hline
\end{tabular}

${ }^{*}$ Note that AE data are reported for all patients treated. This is slightly higher than the number of patients with BP measurements available and reported in the efficacy analysis.

and SBP compared with maintenance on, and uptitration of, amlodipine monotherapy. This is to be expected due to the complimentary modes of actions of the two drugs. Adding an ARB to CCB therapy should promote arterial and venous dilation by blocking the RAS system and attenuate renal hyperfiltration and peripheral edema induced by CCBs. In addition, the negative sodium balance promoted by CCBs may further reinforce the antihypertensive effect of the ARB [28-30].

The greatest treatment differences noted, 7.4/4.2 $\mathrm{mm} \mathrm{Hg}$, were between continuation on A5 monotherapy and switching to T80/A5. Slightly smaller treatment differences of 2.8$3.8 \mathrm{~mm} \mathrm{Hg}$ were observed when patients not at goal with A10 switched to SPC therapy compared with those who continued with A10 monotherapy. This may be expected as patients who are unresponsive to higher doses of monotherapy are often considered more difficult to treat. These small differences in BP may be clinically relevant, as a large meta-analysis found that reductions in SBP even as small as $2 \mathrm{~mm} \mathrm{Hg}$ reduced mortality from stroke by $10 \%$ and mortality from other CV causes by $7 \%$ in middle-aged individuals [31].

In this analysis, patients switched to SPC therapy were more likely to respond to treatment and achieve BP goal than those maintained on monotherapy. In patients not at goal with A5 monotherapy, the odds ratio (OR) of achieving BP goal (<140/90 mm Hg) was 3.43 (95\% CI, 2.54, 4.64) for T80/A5 versus continuing A5 therapy, and for DBP goal (<90 $\mathrm{mm} \mathrm{Hg}$ ), the corresponding OR was 3.00 (95\% CI, 2.22, 4.07). However, approximately half of all patients not at goal (DBP $<90 \mathrm{~mm} \mathrm{Hg}$ ) on either dose of amlodipine monotherapy after 6-8 weeks of treatment achieved DBP goal following a further 8 weeks of continued monotherapy treatment, and $56.7 \%$ of patients achieved DBP goal on switching to more potent monotherapy (uptitration to A10). This suggests that some patients initially unresponsive to monotherapy may eventually achieve BP goal if continued on the same treatment at the same or a higher dose of monotherapy. However, the time taken to achieve BP goal is also an important risk factor [32-36]. Therefore, due to greater likelihood of goal attainment and greater SBP/DBP reduction, early treatment with SPC therapy may be preferable to quickly achieve and maintain BP goal.

The $\mathrm{BP}$ reductions observed with telmisartan/amlodipine SPC therapy in patients not at goal with amlodipine monotherapy are similar to those observed with other ARB/CCB combinations. For example, a study investigating olmesartan/amlodipine in patients with moderate-to-severe hypertension, not at goal with amlodipine monotherapy, adds further support for switching to combination therapy [37]. Following 8 weeks of A5 monotherapy, nonresponders were randomized to receive either placebo plus A5 or a combination of olmesartan $(10,20$, or $40 \mathrm{mg})$ plus A5 for a further 8 weeks. Adjusted mean changes in DBP versus placebo/amlodipine therapy were $-2.0 \mathrm{~mm} \mathrm{Hg}(P=0.0207)$ for olmesartan $10 \mathrm{mg} / \mathrm{A} 5,-3.7 \mathrm{~mm} \mathrm{Hg}(P<0.0001)$ for olmesartan $20 \mathrm{mg} / \mathrm{A} 5$, and $-3.8 \mathrm{~mm} \mathrm{Hg}(P<0.0001)$ for olmesartan $40 \mathrm{mg} / \mathrm{A} 5$. Adjusted mean changes in SBP were $-3.5 \mathrm{~mm} \mathrm{Hg}(P=0.0103),-5.8 \mathrm{~mm} \mathrm{Hg}(P<0.0001)$, and $-7.1 \mathrm{~mm} \mathrm{Hg}(P<0.0001)$, respectively [37].

This is the first pooled analysis of telmisartan/amlodipine SPC therapy in a large number of patients $(n=1891)$ not at goal with $\mathrm{A} 5$ monotherapy, in addition to the retrospective analysis of another study $(n=921)$ in patients not at goal with A10 monotherapy. Limitations of these analyses are that they are retrospective and incorporate Boehringer Ingelheimsponsored studies only. However, the endpoints stipulated in the individual trials are mostly identical to those used in this pooled and retrospective analysis, and results from the two separate analyses are similar. In addition, the use of the Boehringer Ingelheim studies enabled the study of patientlevel data. In each study, criteria for randomization was DBP $>90 \mathrm{~mm} \mathrm{Hg}$. A significant proportion of randomized patients $(15.8-30.2 \%)$ already had SBP $<140 \mathrm{~mm} \mathrm{Hg}$, which partly confounds the analysis of SBP data; however, the analysis of DBP is robust. The results are clinically relevant in terms of the doses investigated and the study design, investigating BP goal attainment with combination therapy in patients not at goal with monotherapy.

\section{Conclusion}

Patients not at goal with A5 or A10 monotherapy achieved significantly greater DBP and SBP reductions compared with continuing with amlodipine monotherapy, and the majority of patients achieved BP goal when switched to telmisartan/amlodipine SPC therapy. Reported adverse events with SPC therapy were similar to or less than those experienced with continued monotherapy. Therefore, the early use of combination therapy, such as the telmisartan/amlodipine 
SPC, may be considered as an approach to quickly reach BP targets. This is of particular relevance to the more difficult-totreat, added-risk, hypertensive patients.

\section{Acknowledgments}

The authors were fully responsible for all content and editorial decisions, were involved at all stages of the paper's development, and have approved the final version. Medical writing assistance, supported financially by Boehringer Ingelheim, was provided by Emma Fulkes, Ph.D., of PAREXEL, during the preparation of this paper.

\section{References}

[1] M. Ezzati, S. Oza, G. Danaei, and C. J. L. Murray, “Trends and cardiovascular mortality effects of state-level blood pressure and uncontrolled hypertension in the United States," Circulation, vol. 117, no. 7, pp. 905-914, 2008.

[2] G. Mancia, S. Laurent, E. Agabiti-Rosei et al., "Reappraisal of European guidelines on hypertension management: a European society of hypertension task force document," Journal of Hypertension, vol. 27, no. 11, pp. 2121-2158, 2009.

[3] A. V. Chobanian, G. L. Bakris, H. R. Black et al., "Seventh report of the Joint National Committee on Prevention, Detection, Evaluation, and Treatment of High Blood Pressure," Hypertension, vol. 42, no. 6, pp. 1206-1252, 2003.

[4] G. Mancia, B. G. De, A. Dominiczak et al., "Guidelines for the management of arterial hypertension: the task force for the management of arterial hypertension of the European Society of Hypertension (ESH) and of the European Society of Cardiology (ESC)," Journal of Hypertension, vol. 25, no. 6, pp. 1105-1187, 2007.

[5] W. C. Cushman, G. W. Evans, R. P. Byington et al., "Effects of intensive blood-pressure control in type 2 diabetes mellitus," The New England Journal of Medicine, vol. 362, no. 17, pp. 1575$1585,2010$.

[6] S. J. Denardo, F. H. Messerli, E. Gaxiola et al., "Coronary revascularization strategy and outcomes according to blood pressure (from the International Verapamil SR-Trandolapril Study [INVEST])," The American Journal of Cardiology, vol. 106, no. 4, pp. 498-503, 2010.

[7] A. Patel, S. MacMahon, J. Chalmers et al., "Effects of a fixed combination of perindopril and indapamide on macrovascular and microvascular outcomes in patients with type 2 diabetes mellitus (the ADVANCE trial): a randomised controlled trial," The Lancet, vol. 370, no. 9590, pp. 829-840, 2007.

[8] G. Mancia, "Role of outcome trials in providing information on antihypertensive treatment: importance and limitations," The American Journal of Hypertension, vol. 19, no. 1, pp. 1-7, 2006.

[9] M. A. Tedesco, F. Natale, and R. Calabrò, "Effects of monotherapy and combination therapy on blood pressure control and target organ damage: a randomized prospective intervention study in a large population of hypertensive patients," Journal of Clinical Hypertension, vol. 8, no. 9, pp. 634-641, 2006.

[10] D. S. Wald, M. Law, J. K. Morris, J. P. Bestwick, and N. J. Wald, "Combination therapy versus monotherapy in reducing blood pressure: meta-analysis on 11,000 participants from 42 trials," The American Journal of Medicine, vol. 122, no. 3, pp. 290-300, 2009.
[11] A. H. Gradman, J. N. Basile, B. L. Carter, and G. L. Bakris, "Combination therapy in hypertension," Journal of Clinical Hypertension, vol. 13, no. 3, pp. 146-154, 2011.

[12] National Institute for Health and Clinical Excellence, "Hypertension: clinical management of primary hypertension in adults," NICE clinical guidance webpages, 2012, http://guidance .nice.org.uk/CG127.

[13] S. Bangalore and L. Ley, "Improving treatment adherence to antihypertensive therapy: the role of single-pill combinations," Expert Opinion on Pharmacotherapy, vol. 13, no. 3, pp. 345-355, 2012.

[14] G. L. Bakris, P. A. Sarafidis, M. R. Weir et al., "Renal outcomes with different fixed-dose combination therapies in patients with hypertension at high risk for cardiovascular events (ACCOMPLISH): a prespecified secondary analysis of a randomised controlled trial," The Lancet, vol. 375, no. 9721, pp. 1173-1181, 2010.

[15] Micardis, "Summary of product characteristics," 2012, http:// www.ema.europa.eu/.

[16] S. Yusuf, K. K. Teo, J. Pogue et al., "Telmisartan, ramipril, or both in patients at high risk for vascular events," The New England Journal of Medicine, vol. 358, no. 15, pp. 1547-1559, 2008.

[17] T. W. Littlejohn III, C. R. Majul, R. Olvera et al., "Results of treatment with telmisartan-amlodipine in hypertensive patients," Journal of Clinical Hypertension, vol. 11, no. 4, pp. 207-213, 2009.

[18] T. W. Littlejohn III, C. R. Majul, R. Olvera et al., "Original research: telmisartan plus amlodipine in patients with moderate or severe hypertension: results from a subgroup analysis of a randomized, placebo-controlled, parallel-group, $4 \times 4$ factorial study," Postgraduate Medicine, vol. 121, no. 2, pp. 5-14, 2009.

[19] R. M. Guthrie, B. Dahlöf, K. A. Jamerson et al., "Efficacy and tolerability of telmisartan plus amlodipine in added-risk hypertensive patients," Current Medical Research and Opinion, vol. 27, no. 10, pp. 1995-2008, 2011.

[20] S. Neldam, M. Lang, and R. Jones, “Telmisartan and amlodipine single-pill combinations vs amlodipine monotherapy for superior blood pressure lowering and improved tolerability in patients with uncontrolled hypertension: results of the TEAMSTA-5 study," Journal of Clinical Hypertension, vol. 13, no. 7, pp. 459-466, 2011.

[21] J. Neutel, G. Mancia, H. Black et al., "Single-pill combination of telmisartan $80 \mathrm{Mg} /$ Amlodipine $10 \mathrm{Mg}$ provides superior blood pressure reductions in patients with severe hypertension: teamsta severe Htn study: Ht.1.04," Journal of Hypertension, vol. 28, p. e46, 2010.

[22] W. Oigman, M. F. Neves, and R. A. Gismondi, "Combination of telmisartan plus amlodipine in the treatment of hypertension: review of results," Expert Review of Cardiovascular Therapy, vol. 8, no. 11, pp. 1509-1517, 2010.

[23] A. Sharma, A. Bagchi, S. B. Kinagi, Y. K. Sharma, V. P. Baliga, and C. Bollmall, "Results of a comparative, phase III, 12-week, multicenter, prospective, randomized, double-blind assessment of the efficacy and tolerability of a fixed-dose combination of telmisartan and amlodipine versus amlodipine monotherapy in Indian adults with stage II hypertension," Clinical Therapeutics, vol. 29, no. 12, pp. 2667-2676, 2007.

[24] W. B. White, T. W. Littlejohn, C. R. Majul et al., "Effects of telmisartan and amlodipine in combination on ambulatory blood pressure in stages 1-2 hypertension," Blood Pressure Monitoring, vol. 15, no. 4, pp. 205-212, 2010.

[25] S. Neldam, C. Edwards, and R. Jones, "Switching patients with uncontrolled hypertension on amlodipine $10 \mathrm{mg}$ to single-pill 
combinations of telmisartan and amlodipine: results of the TEAMSTA-10 study," Current Medical Research and Opinion, vol. 27, no. 11, pp. 2145-2153, 2011.

[26] “BI Data on file. Study 1235.13," 2012.

[27] D. Zhu, D. Hu, L. Cheng, and H. Chenglai, "Single-pill combination of telmisartan $80 \mathrm{mg} /$ amlodipine $5 \mathrm{mg}$ provides superior blood pressure reductions on hypertensive patients who fail to respond adequately with amlodipine $5 \mathrm{mg}$ monotherapy.," ISH Abstract 698.00, vol. 98, supplement 2, 2012.

[28] N. B. Mistry, A. S. Westheim, and S. E. Kjeldsen, “The angiotensin receptor antagonist valsartan: a review of the literature with a focus on clinical trials," Expert Opinion on Pharmacotherapy, vol. 7, no. 5, pp. 575-581, 2006.

[29] A. Quan, K. Chavanu, and J. Merkel, "A review of the efficacy of fixed-dose combinations olmesartan medoxomil/ hydrochlorothiazide and amlodipine besylate/benazepril in factorial design studies," The American Journal of Cardiovascular Drugs, vol. 6, no. 2, pp. 103-113, 2006.

[30] D. A. Sica, "Rationale for fixed-dose combinations in the treatment of hypertension: the cycle repeats," Drugs, vol. 62, no. 3, pp. 443-462, 2002.

[31] S. Lewington, R. Clarke, N. Qizilbash, R. Peto, and R. Collins, "Age-specific relevance of usual blood pressure to vascular mortality: a meta-analysis of individual data for one million adults in 61 prospective studies," The Lancet, vol. 360, no. 9349, pp. 1903-1913, 2002.

[32] M. J. Brown, G. T. McInnes, C. C. Papst, J. Zhang, and T. M. MacDonald, "Aliskiren and the calcium channel blocker amlodipine combination as an initial treatment strategy for hypertension control (ACCELERATE): a randomised, parallel-group trial," The Lancet, vol. 377, no. 9762, pp. 312-320, 2011.

[33] B. Dahlöf, P. S. Sever, N. R. Poulter et al., "Prevention of cardiovascular events with an antihypertensive regimen of amlodipine adding perindopril as required versus atenolol adding bendroflumethiazide as required, in the Anglo-Scandinavian Cardiac Outcomes Trial-Blood Pressure Lowering Arm (ASCOTBPLA): a multicentre randomised controlled trial," The Lancet, vol. 366, no. 9489, pp. 895-906, 2005.

[34] S. Julius, S. E. Kjeldsen, M. Weber et al., "Outcomes in hypertensive patients at high cardiovascular risk treated with regimens based on valsartan or amlodipine: the VALUE randomised trial," The Lancet, vol. 363, no. 9426, pp. 2022-2031, 2004.

[35] E. O. Ofili, K. C. Ferdinand, E. Saunders et al., "Irbesartan/ HCTZ fixed combinations in patients of different racial/ethnic groups with uncontrolled systolic blood pressure on monotherapy," Journal of the National Medical Association, vol. 98, no. 4, pp. 618-626, 2006.

[36] M. A. Weber, S. Julius, S. E. Kjeldsen et al., "Blood pressure dependent and independent effects of antihypertensive treatment on clinical events in the VALUE Trial," The Lancet, vol. 363, no. 9426, pp. 2049-2051, 2004.

[37] M. Volpe, P. Brommer, U. Haag, and C. Miele, "Efficacy and tolerability of olmesartan medoxomil combined with amlodipine in patients with moderate to severe hypertension after amlodipine monotherapy: a randomized, double-blind, parallel-group, multicentre study," Clinical Drug Investigation, vol. 29, no. 1, pp. 11-25, 2009. 


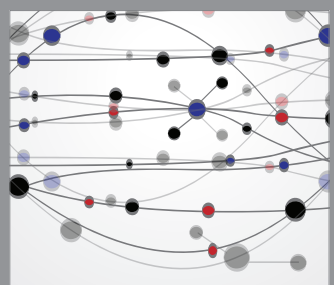

The Scientific World Journal
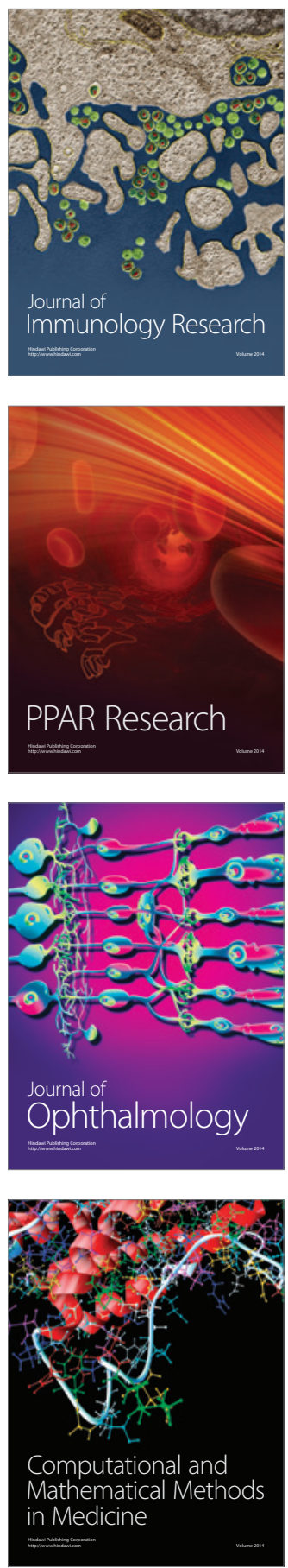

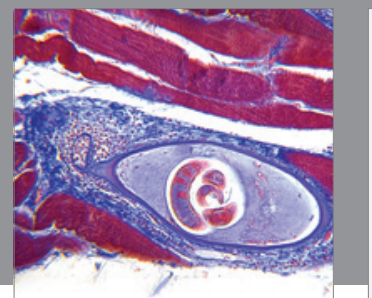

Gastroenterology

Research and Practice
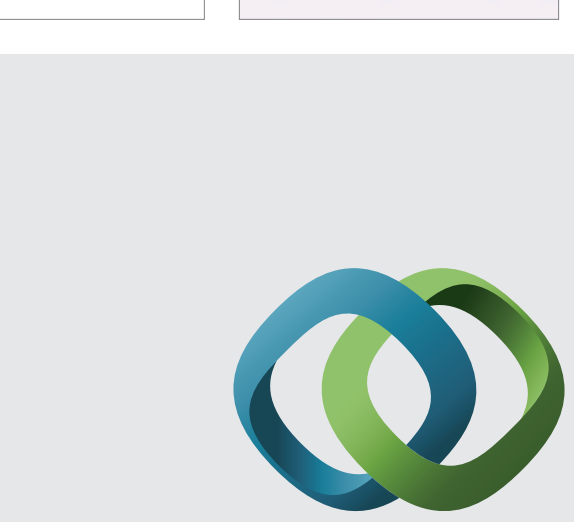

\section{Hindawi}

Submit your manuscripts at

http://www.hindawi.com
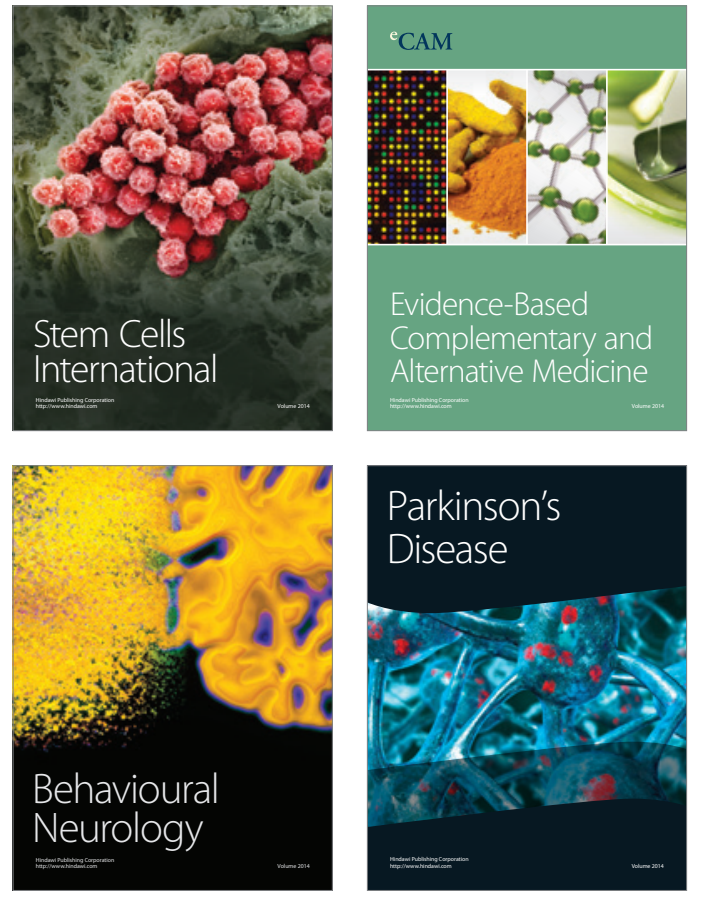
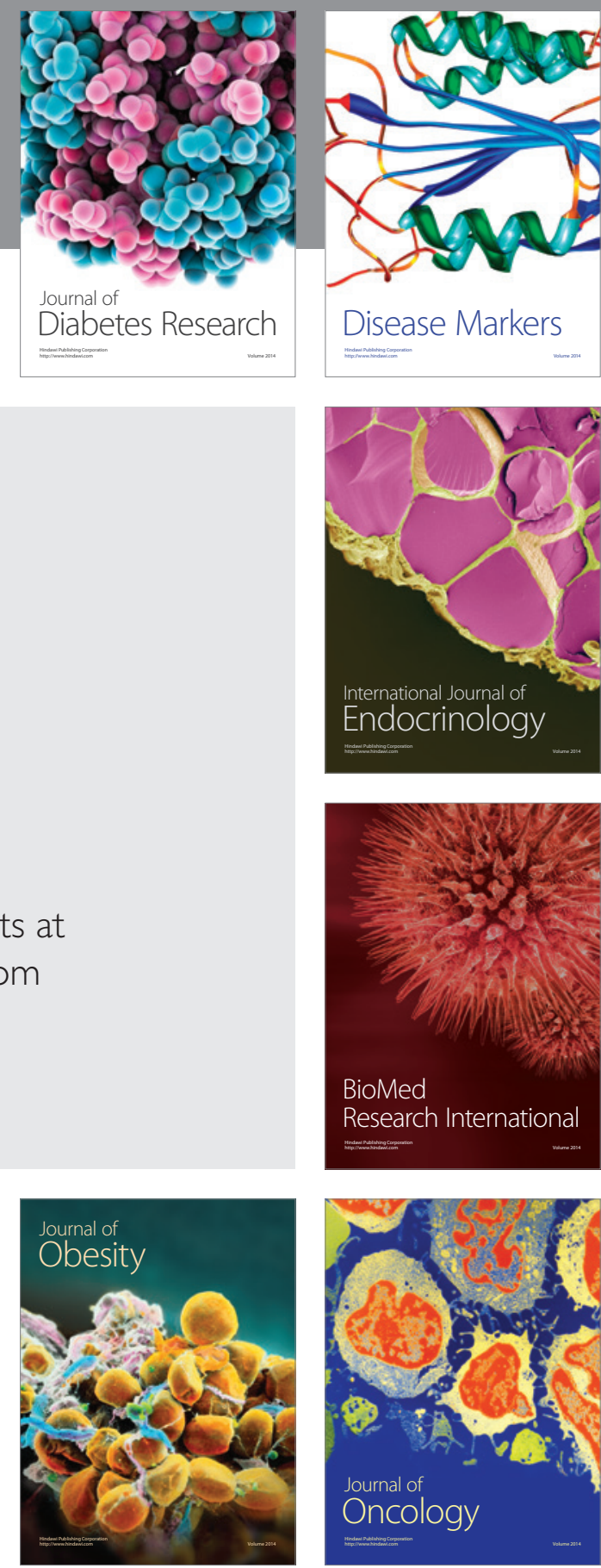

Disease Markers
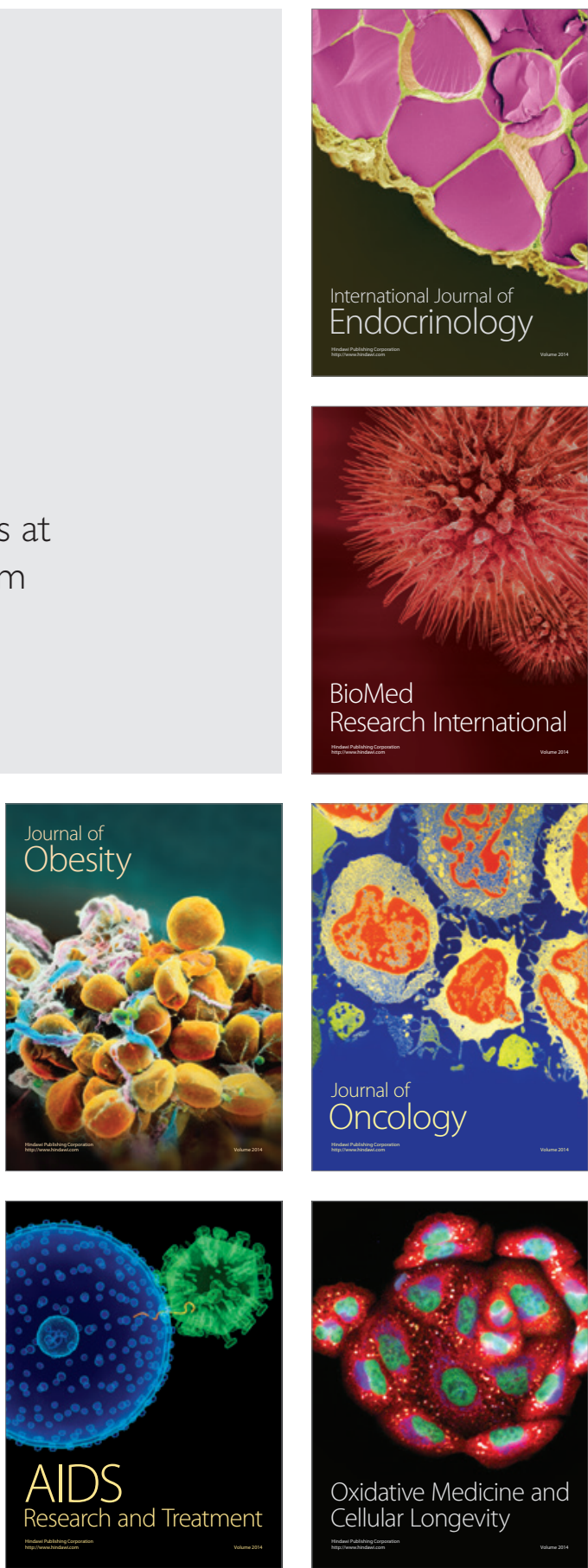